\title{
Indicadores Críticos para Avaliação de Habilidades Sociais Educativas em Situações Interpessoais Difíceis
}

\author{
Adriana Benevides Soares ${ }^{1,2, *}$ (D, Pedro Vitor Souza Rodrigues ${ }^{1}$ (D, \& Luciana Mourão ${ }^{1}$ (D) \\ ${ }^{1}$ Universidade Salgado de Oliveira, Niterói, Rio de Janeiro, Brasil \\ ${ }^{2}$ Universidade do Estado do Rio de Janeiro, Rio de Janeiro, RJ, Brasil
}

\begin{abstract}
RESUMO - No processo ensino-aprendizagem, a sala de aula é afetada por conflitos interpessoais. Isso exige que o professor lide com situações difíceis durante grande parte do tempo de aula. Este estudo visou construir indicadores de criticidade associando o grau de desconforto emocional, a frequência e a probabilidade de ocorrência de habilidades sociais educativas diante de situações interpessoais consideradas difíceis em sala de aula. Participaram 200 professores do Ensino Fundamental de escolas públicas e privadas. O inventário contou com 19 itens. Foram encontradas sete situações pouco críticas, oito moderadas e quatro muito críticas. Esses resultados podem levar à discussão de como os professores lidam com essas situações e o quanto são capacitados a exercer sua profissão com competência social.
\end{abstract}

PALAVRAS-CHAVE: habilidades sociais educativas, treinamento de habilidades sociais, professores do ensino fundamental

\section{Critical Indicators for Assessing Educational Social Skills in Difficult Interpersonal Situations}

\begin{abstract}
During the teaching-learning process, the classroom is affected by interpersonal conflicts. This requires the teacher to deal with difficult situations for much of the class time. In this context, this study aimed to construct indicators of criticality by associating frequency of occurrence, degree of emotional discomfort and probability of occurrence of educational social skills in the face of interpersonal situations considered difficult to class. 200 teachers from public and private schools attended. The inventory had 19 items. There were seven uncritical situations, eight moderate and four very critical. These results may lead to a discussion of how teachers deal with these situations and how well they are able to exercise their profession with social competence.
\end{abstract}

KEYWORDS: educational social skills, social skills training, elementary school teachers

Aescola é um ambiente caracterizado pela responsabilidade de proporcionar ao cidadão a possibilidade de acessar os seus direitos, constituídos de forma que o indivíduo seja operante e autônomo na sociedade em que se encontra. $\mathrm{O}$ desafio de desenvolver o estudante demanda métodos pedagógicos para o ensino de conhecimentos sobre o mundo circundante, incluindo competências básicas (Gondim et al., 2016) que compreendem também a educação em valores para uma convivência saudável em sociedade. O professor, agente principal na execução dessa tarefa, precisa se preparar continuamente para os diversos dilemas escolares que o dia a dia escolar configura (Jacomini, 2009), pois fatores como a indisciplina e o baixo aproveitamento dos alunos são obstáculos ao trabalho docente. Assim, existe um debate sobre o conteúdo da formação docente capaz de favorecer o processo de desenvolvimento escolar dos estudantes.

Magalhães Jr. e Oliveira (2005) sustentam que as oportunidades para a formação especializada de professores para o Ensino Fundamental no Brasil são muito escassas. Muitos professores do Ensino Fundamental têm Licenciatura Plena em Biologia ou História Natural, contudo, esses cursos geralmente os preparam para conteúdos voltados para o Ensino Médio, sem apresentar uma formação pedagógica diferenciada entre os níveis Fundamental e Médio.

Mourão e Esteves (2013) apontam que a maioria dos profissionais do primeiro ciclo da Educação Básica são

*E-mail: adribenevides@gmail.com

- Submetido: 04/10/2017; Aceito: 09/09/2020. 
pedagogos. Segundo as autoras, a grade curricular dos cursos de Pedagogia se concentra nos Fundamentos e na História da Educação, de tal sorte que os conhecimentos específicos do curso de Pedagogia não proporcionam competências educacionais efetivas para as séries iniciais do Ensino Fundamental, como também não suprem deficiências consideráveis em termos de cultura geral ou de conhecimentos básicos do Ensino Fundamental. Para além disso, argumentam que os estudantes de Pedagogia são, em muitos casos, os alunos com as menores médias nos resultados do Exame Nacional do Ensino Médio (ENEM).

Esse quadro pode resultar em professores incapazes de ensinar, porque concentram-se em repetir os textos pedagógicos sem reflexão crítica. Embora a realidade apurada sobre a docência do Ensino Fundamental apresente, de modo geral, uma formação básica insuficiente, o seu conteúdo é definido e regulamentado no Brasil. A Lei de Diretrizes e Bases da Educação (LDB) regimenta o sistema educacional brasileiro público ou privado, da Educação Básica ao Ensino Superior. A promulgação da primeira LDB ocorreu em 1961 (LDB 4024/61) e a atual, em 2013 (Lei n ${ }^{\circ}$ 12.796, de 04/04/2013), que altera a antiga LDB de 1996 ao estabelecer um aumento no número de anos obrigatórios de permanência na escola (dos quatro aos 17 anos de idade).

Com essa mudança legal, as escolas receberam um prazo para se prepararem quanto à execução das novas regras até o ano de 2016. O fato de aumentar o número de anos da educação infantil e de tornar obrigatório o ensino até os 17 anos de idade faz com que aumente a demanda por professores, uma vez que haverá mais turmas nas escolas. Além disso, como os alunos ingressarão mais cedo na vida escolar, são esperadas repercussões para o Ensino Fundamental, uma vez que as crianças terão mais oportunidades de desenvolver as competências demandadas para essa etapa educacional. A esse respeito, a legislação estabelece que a formação básica no Ensino Fundamental deve englobar o pleno domínio da leitura, da escrita e do cálculo; o entendimento do ambiente natural e social, do sistema político, da tecnologia, das artes e dos valores que compõem a sociedade; o desenvolvimento da capacidade de aprendizagem, que inclui conhecimentos, habilidades, atitudes e valores; e o fortalecimento dos laços familiares e da solidariedade humana e tolerância recíproca.

Para efeito de comparação internacional, Garcia et al. (2011) descrevem os parâmetros propostos pelo New South Wales Institute of Teachers para credenciar a formação de professores de ciências para o Ensino Fundamental na Austrália. Os critérios australianos incluem que o professor habilitado deve: (I) dominar os conhecimentos que pretende ensinar aos alunos; (II) saber que tipo de conhecimentos são pré-requisitos para a aprendizagem de níveis mais complexos; (III) planejar as etapas graduais de ensino progressivo; (IV) transmitir de forma clara e eficaz as instruções aos seus alunos; (V) prover contingências nas quais os alunos errem minimamente (ambiente seguro) e sejam motivados a resolver as atividades (ambientes desafiadores); (VI) ficar atento ao autodesenvolvimento de repertórios de ensino mais eficazes, por meio da melhoria em conhecimentos educacionais práticos ou pelos efeitos naturais positivos de seu trabalho em aula; e (VII) manter-se vinculado à comunidade profissional. Assim, os critérios de formação no Ensino Fundamental precisam ir além do ensino de conhecimentos científicos, entrando no âmbito social.

No Brasil, Del Prette e Del Prette (2003) ressaltam que, para atender diversas demandas interpessoais no contexto de trabalho, as competências sociais são, em geral, objetivos de formações profissionais, nem sempre alcançados na prática. Os autores destacam que o contexto educacional brasileiro investe bastante no desenvolvimento das capacidades analíticas (raciocínio crítico) e instrumentais (produtividade técnica), mas negligencia o progresso interpessoal do aluno.

Nessa perspectiva, Perrenoud (1999) utiliza o conceito de competência para ampliar os critérios de formação docente. Embora existam múltiplos significados para o termo, o autor define competência como "uma capacidade de agir eficazmente em um determinado tipo de situação, apoiada em conhecimentos, mas sem limitar-se a eles" (p.7). Salienta que, para ensinar conhecimento, basta ser minimamente erudito, contudo, é necessário possuir competência para formar alguém. Segundo Perrenoud et al. (2002), algumas formações de professores restringem-se ao domínio de saberes e de princípios pedagógicos e didáticos gerais, sem o ensino de competências para o favorecimento da aprendizagem em contextos diversos em que os alunos se encontram. Perrenoud (2000) esclarece que uma das competências principais do professor é organizar e dirigir situações de aprendizagem, pois é preciso ensinar mesmo quando os alunos se agitam frequentemente ou não se esforçam. Nesse contexto, os estudos sobre Habilidades Sociais podem contribuir, pois visam identificar e treinar repertórios que produzam efeitos desejáveis às interações interpessoais nos mais diversos ambientes em que as pessoas se relacionam. Assim, o repertório de habilidades sociais educativas pode contribuir para a administração de situações interpessoais escolares consideradas difíceis em aula, isto é, para o manejo de situações, comportamentos estudantis ou circunstâncias interpessoais entre o professor e os alunos que dificultam o aprendizado dos conteúdos propostos nas disciplinas ou desfavorecem a organização da sala para o ensino. Além disso, por situações interpessoais difíceis pode-se também entender especialmente aquelas que exigem o exercício das habilidades sociais assertivas que requerem a manifestação de direitos individuais e a expressão de pensamentos e sentimentos de forma objetiva, clara, honesta e adequada, respeitando o direito dos outros (Del Prette \& Del Prette, 2001).

De fato, as habilidades sociais podem ser entendidas como uma classe de comportamentos emitidos em contexto interpessoal que expressa sentimentos, atitudes, desejos, opiniões ou direitos do indivíduo de modo adequado à 
situação, respeitando as outras pessoas, solucionando problemas imediatos e evitando problemas posteriores (Caballo, 1996). Nesse âmbito, "competência social" é definida como a efetividade do comportamento habilidoso em certa ocasião ou, conforme McFall (1982), a avaliação da qualidade da performance social do indivíduo em uma situação particular. As habilidades sociais educativas, por sua vez, são "aquelas intencionalmente voltadas para a promoção do desenvolvimento e da aprendizagem do outro, em situação formal ou informal" (Del Prette \& Del Prette, 2001, p. 94). Assim, as habilidades sociais são recursos preventivos ou redutores da violência que aumentam a qualidade na relação professor-aluno e o desempenho acadêmico (Gomes et al., 2013). Para demonstrar essa efetividade, têm sido desenvolvidas pesquisas sobre habilidades sociais em professores, como apresentamos a seguir.

O estudo de Soares e Mello (2009), com 264 professores do nível infantil ao superior e 263 não professores, mostrou que os professores em geral apresentam maior repertório de habilidades sociais em comparação com o grupo de não professores. Esse resultado sugere que o professor pode desenvolver esse repertório rico em ações de formação profissional e a partir do histórico de participação no aprendizado dos alunos. Corrêa (2008), inclusive, defende como válida a aplicação de um Treinamento de Habilidades Sociais (THS) para professores, visando estabelecer um ambiente educativo socialmente competente.

$\mathrm{Na}$ outra ponta dessa relação, encontram-se estudos que, em vez de focalizarem nas habilidades sociais dos professores, voltaram-se para as habilidades de alunos, mantendo o enquadramento no contexto acadêmico. Assim, o estudo de Wagner et al. (2019) consistiu em uma intervenção grupal no ensino superior. Os autores concluíram que o THS é uma intervenção que pode trazer benefícios aos participantes, com melhoras na interação grupal e no aumento da assertividade em situações difíceis.

Lima, Soares e Souza (2019) também testaram THS para universitários em situações consideradas difíceis no contexto acadêmico. A intervenção relatada por eles foi realizada com 11 universitários que cursavam o primeiro ano de graduação em instituições públicas e privadas. $\mathrm{O}$ experimento foi conduzido em 12 sessões semanais, com duração de 120 minutos cada, com a abordagem de temas como falar em público, lidar com autoridade, lidar com críticas, fazer elogios, entre outros. Os autores identificaram que todos os participantes tiveram ganhos quanto à aquisição de habilidades sociais.

De maneira similar, Soares et al. (2019) estudaram as relações preditivas entre as variáveis habilidades sociais e estratégias de coping na adaptação à universidade em cinco situações consideradas de difícil manejo, a saber: "Pedir a um colega que desligue seu celular na aula", "Apresentar trabalho em aula", "Pedir aos colegas que evitem de lanchar na sala", "Mobilizar colegas para reivindicar direitos", "Receber críticas do professor". Os autores apontaram que o estudante que recorre às estratégias de enfrentamento Focalizado no Problema e na Busca de Suporte Social lida melhor com questões de difícil manejo na universidade. A estratégia de enfrentamento Focalizado no Problema e a Habilidade Social de Autoafirmação na Expressão de Sentimento Positivo apresentaram maior impacto nos escores de adaptação acadêmica.

A pesquisa de Gonçalves et al. (2005) já caminha em outro sentido, pois focaliza na questão dos conflitos e da violência no ambiente escolar. Os autores realizaram uma investigação com dez professores de alunos adolescentes de periferia para realizar uma formação continuada e identificaram dificuldades dos docentes no seu exercício profissional, com o grande número de alunos nas turmas. Os docentes manifestaram preocupação em orientar os alunos em temáticas como drogas e sexo, conservação do espaço físico escolar, indisciplina, violência e falta de motivação. Já a pesquisa de Alencar e Fleith (2008) objetivou investigar a percepção de professores do Ensino Fundamental $(\mathrm{n}=398)$ referente às barreiras para o desenvolvimento criativo de seus alunos. As principais dificuldades foram: elevado número de alunos em sala de aula, alunos com dificuldades de aprendizagem, baixo reconhecimento do trabalho do professor, extensão do programa a ser cumprido no decorrer do ano letivo, desinteresse do aluno pelo conteúdo ministrado e escassez de material didático disponível na escola. Em um sentido complementar, a pesquisa de Rosso e Camargo (2013) analisa as representações sociais do desgaste no trabalho docente, a partir de 38 entrevistas com este público-alvo. $\mathrm{O}$ corpus dos discursos apontou as classes "família ausente", "valorização da educação" e "sala de aula", revelando uma representação social centrada no reconhecimento da docência que se desloca entre os planos doméstico, social e da sala de aula. Esse desgaste é algo que precisa ser considerado, porque já há estudos que apontam para a prevalência da síndrome de Burnout em professores, apontando questões como gênero, idade, carga horária, número de alunos e vinculação com a rede pública como fatores associados a tal processo de adoecimento e de falta de realização docente (Carlotto, 2011).

Alguns autores evidenciam que muitos professores explicam de forma reducionista ou equivocada a indisciplina dos alunos, por exemplo, como algo inerente à adolescência, brincadeira própria da idade, produto dos tempos atuais modernos ou responsabilizando apenas o aluno ou a família (Blasco, 1997; Cury et al., 2012; Ferreira et al., 2016). No entanto, alguns estudos desmistificam esses argumentos. $\mathrm{Na}$ pesquisa realizada por Cury et al. (2012) com dez professores do Ensino Fundamental, foi apontado que os educadores desconsideraram múltiplos fatores envolvidos na questão, atribuindo a indisciplina à sociedade, à mídia, à família e aos próprios alunos, isentando-se de qualquer influência nesse processo. Nesse sentido, falta uma compreensão dos educadores de que a indisciplina é também um fenômeno produzido pelas condições escolares. A rotulação dos alunos 
devido à indisciplina pode, inclusive, gerar preconceitos e desmotivar mudanças.

Um estudo com resultados semelhantes ao de Cury et al. (2012), mas com uma amostra mais ampla (analisou comentários de 414 professores em redes sociais), chegou a conclusões semelhantes. A análise de representações sociais sobre indisciplina discente a partir dos discursos nas redes sociais mostra um grupo minoritário de docentes que associa a indisciplina dos alunos a aspectos de natureza relacional, levando em consideração a interação dos fatores que a produzem. Contudo, a representação social dominante entre os docentes considera que a indisciplina discente é pautada em atitudes defensivas, compreensão heterônoma e explicação exógena ao ambiente escolar e pedagógico.

A conclusão que tais estudos permitem é a de que as situações interpessoais em aula podem derivar de diversos fatores, o que demanda uma reflexão dos professores acerca dos determinantes dos dilemas escolares como a indisciplina, os conflitos e a violência. Um olhar mais compreensivo e que permita assumir sua responsabilidade nesse processo pode permitir o desenvolvimento de ações que contribuam para uma atuação mais sócio-habilidosa dos docentes no contexto escolar. Nesse sentido, é preciso mapear as situações interpessoais consideradas difíceis, a fim de que se possa desenvolver estratégias para favorecer a sua administração. Sendo assim, o objetivo deste estudo é construir um inventário de situações interpessoais difíceis no contexto educativo do Ensino Fundamental II. Para a identificação dessas situações difíceis, são considerados conjuntamente três componentes: o grau de desconforto emocional, a frequência e a probabilidade de ocorrência de habilidades sociais educativas.

\section{MÉTODO}

\section{Participantes}

A amostra foi de conveniência e participaram do estudo 200 professores do segundo ciclo do Ensino Fundamental de escolas públicas $(n=125)$ e privadas $(n=75)$. A idade dos participantes variou entre 24 e 45 anos, sendo $98 \%$ mulheres. Quanto ao estado civil, a amostra se dividiu em solteiros $(\mathrm{n}=46)$, casados (n=121) e outros (33). Em relação à classe social, considerando o atual Critério Brasil, as classes identificadas foram: A ( $\mathrm{n}=19), \mathrm{B} 1(\mathrm{n}=79), \mathrm{B} 2(\mathrm{n}=83)$ e C1 $(\mathrm{n}=19)$.

\section{Instrumentos}

$\mathrm{O}$ instrumento usado na pesquisa foi desenvolvido especificamente para a presente pesquisa e as respostas habilidosas sugeridas para cada item foram elaboradas de acordo com o Sistema de Habilidades Sociais Educativas - HSE (Del Prette \& Del Prette, 2008), que é uma sistematização confiável para o registro de HSE em situação natural e estruturada. O objetivo de tal sistema é nortear programas de desenvolvimento de habilidades para agentes educativos. Esse sistema divide as HSE em quatro categorias gerais, que são: (I) estabelecer contextos interativos potencialmente educativos (habilidade de propiciar contextos discriminativos para a participação do aluno); (II) transmitir ou expor conteúdos sobre habilidades sociais (habilidade de expor de forma dialogada habilidades sociais necessárias para interações harmoniosas e produtivas); (III) estabelecer limites e disciplina (habilidade de limitar comportamentos incompatíveis com o ambiente socioeducativo) e (IV) monitorar positivamente (habilidade de supervisionar e reforçar a participação do aluno).

Assim, tal sistema foi adaptado para o presente estudo a fim de que todas as respostas sociais educativas sugeridas para o inventário fossem contempladas nas classificações. Para atender a tal critério, a primeira versão do inventário foi composta por 30 itens, que foram avaliados por cinco juízes em quatro dimensões: clareza de linguagem, pertinência prática, relevância teórica e dimensão teórica. Após essa revisão, foram mantidos os itens que atenderam ao critério de $80 \%$ de concordância entre os juízes.

A versão do inventário resultante da análise de juízes ficou composta por 19 itens e permitiu abordar diferentes situações interpessoais difíceis, com análise de três elementos em cada uma dessas situações: o desconforto emocional gerado, a frequência de ocorrência dessas situações no ambiente escolar e a probabilidade que o professor percebe de agir de modo competente se essa situação ocorrer. Cada item foi avaliado pelo respondente considerando três critérios, a saber: (I) a frequência em que a situação apresentada ocorre em sala de aula, assinalando "sempre ocorre", "geralmente ocorre", "raramente ocorre" ou "nunca ocorre"; (II) o grau de desconforto (ansiedade ou mal estar percebido ou sentido) para cada uma das situações, variando entre "nada", "um pouco", "razoável" e "muito"; e (III) a probabilidade de se comportar do modo habilidoso indicado no item se essa situação ocorrer, optando por "sempre faço", "geralmente faço", "raramente faço" ou "nunca faço".

\section{Procedimentos de Coleta de Dados}

O projeto de pesquisa foi aprovado pelo comitê de Ética da Universidade e todos os participantes assinaram o Termo de Consentimento Livre e Esclarecido. Os itens foram elaborados a partir de três fontes de pesquisa: (1) entrevistas com seis professores que atuam no Ensino Fundamental de escolas públicas e privadas; (2) revisão de literatura sobre situações interpessoais difíceis em sala; e (3) prática profissional própria, como psicólogo escolar que permitiu observações e 
acesso direto a esses conflitos escolares. Nessa fase, os dados coletados foram transformados em afirmativas de modo que cada questão fosse clara, concreta, com significado para o respondente e abordando somente um conteúdo.

A coleta de dados seguinte foi realizada a partir de uma pesquisa no formato lápis e papel, aplicada em escolas públicas e particulares com professores que lecionavam no Ensino Fundamental II. Antes de o contato com os professores, foi solicitada autorização às escolas e explicados os objetivos da pesquisa e o caráter sigiloso dos dados obtidos. Os professores responderam à pesquisa individualmente e foram informados de que suas respostas seriam consideradas de forma agrupada na geração de análises estatísticas. Também foi garantido aos participantes o direito de interromperem a pesquisa a qualquer momento, se assim o desejassem e sem a necessidade de justificar sua decisão. Nenhum dos dirigentes das escolas teve acesso às respostas individuais de seus professores.

\section{Procedimentos de Análise de Dados}

Os dados foram analisados a partir de estatísticas descritivas, a fim de serem construídos indicadores críticos
(IC) sobre as situações elencadas no inventário. Na análise, identificamos que os casos omissos (missings) não eram numerosos (menos de 5\%) e não apresentavam um padrão, quer seja em relação aos respondentes, quer seja em relação às variáveis. Decidimos, então, que eles poderiam ser substituídos pela mediana. Na coluna da "probabilidade", os números foram invertidos de tal sorte que, quanto maior fosse o número assinalado, menor a probabilidade de ocorrência da habilidade social educativa.

A fórmula que utilizamos para chegar aos coeficientes de criticidade pode ser representada por " $\mathrm{IC}=\mathrm{F}$ x D x P", onde $\mathrm{F}=$ frequência em que a situação ocorre; $\mathrm{D}=$ grau de desconforto ocasionado pela situação; e $\mathrm{P}=$ probabilidade de a pessoa não conseguir comportar-se do modo habilidoso. Com base nesses parâmetros, concluímos que o fator é mais crítico quanto: (I) maior for a frequência; (II) maior for o desconforto emocional; e (III) menor for a probabilidade de desempenho habilidoso. Após o cálculo de tal índice de criticidade, realizamos análises descritivas a fim de apontar quais são as situações interpessoais mais difíceis no contexto educativo do Ensino Fundamental II, a partir de estatística descritiva e de pontos de corte do que seria considerado pouco crítico, moderadamente crítico ou muito crítico.

\section{RESULTADOS}

A Tabela 1 apresenta os resultados obtidos em relação aos indicadores críticos das situações difíceis que podem ser vividas em sala de aula. Os coeficientes de criticidade foram categorizados em três grupos, divididos pela variação numérica entre 1 e 64 conforme os valores da mediana, estabelecendo os seguintes critérios: 1 a $8-$ pouco crítico; 8,1 a 17,9 - moderadamente crítico; e 18 em diante - muito crítico.

A análise da Tabela 1 permite concluir que foram consideradas pouco críticas $36,9 \%$ das situações, a saber: (S10) quando o aluno tenta responder a uma pergunta antes de ela ser completamente feita, (eu o faço aguardar até a questão ser totalmente colocada); (S11) quando o aluno utiliza algum aparelho eletrônico (celular, tablet, etc.), eu digo que desligue e guarde o aparelho; (S12) quando o aluno porta objetos perigosos e proibidos na escola, eu o conduzo para a coordenação; (S13) quando o aluno debocha de algum comportamento meu, eu o oriento que se expresse adequadamente em relação a mim; (S14) quando o aluno sai de sala no intervalo de aula, eu o faço solicitar permissão a mim para isso; (S15) quando o aluno fica apático durante a aula, eu o incentivo a participar da atividade; (S19) quando o aluno fica tocando em sua genitália, eu o oriento a utilizar um espaço privado para esse comportamento. A análise aponta para médias que representaram situações menos frequentes, com baixo grau de desconforto e maiores chances de os docentes agirem de forma pouco habilidosa. Nessa categoria, as médias da frequência variaram entre 1,03 e 1,61; já as médias do fator desconforto variaram entre 1,11 e 1,64, enquanto as médias da probabilidade de não se comportar habilidosamente variaram entre 3,24 e 3,84.

A análise de dados aponta para uma predominância da categoria de situações moderadamente críticas $(42,1 \%)$, na qual se encontraram as seguintes situações: (S02) quando o aluno me desafia a obrigá-lo a participar de alguma atividade, eu o oriento que expresse suas dificuldades; (S03) quando o aluno age violentamente (chuta, soca ou bate, utilizando ou não um objeto), eu o detenho em sua agressão; (S04) quando o aluno fala palavrões, eu o oriento que fale sem usar palavras desse tipo; (S06) quando o aluno perturba (empurrando, jogando objetos ou falando) outro colega, eu o oriento a se relacionar adequadamente; (S08) quando o aluno corre em sala de aula, eu explico que não é o momento e nem o espaço adequado para essa prática; (S09) quando os alunos não expressam suas dúvidas sobre a matéria, eu os incentivo a exporem suas opiniões ou dúvidas; (S16) quando o aluno se recusa a interagir com outro colega, eu o oriento a se relacionar adequadamente com ele; (S17) quando o aluno se recusa a interagir com todos os seus colegas, eu o oriento a se relacionar adequadamente com eles.

A Tabela 1 evidencia que as médias representaram situações com recorrência intermediária como ligeiramente desconfortáveis e com uma probabilidade um pouco acentuada de o professor agir de forma não habilidosa. As médias da frequência variaram entre 1,93 e 2,56, enquanto as médias do fator desconforto ficaram entre 1,94 e 2,43 e 
Tabela 1

Demonstração da análise dos resultados para conclusão dos indicadores de criticidade

\begin{tabular}{|c|c|c|c|c|c|c|}
\hline \multirow{2}{*}{ Situação } & \multirow{2}{*}{$\begin{array}{c}\text { Frequência (F) } \\
\text { Média (DP) }\end{array}$} & \multirow{2}{*}{$\begin{array}{c}\text { Desconforto (D) } \\
\text { Média (DP) }\end{array}$} & \multirow{2}{*}{$\begin{array}{c}\text { Probabilidade (P) } \\
\text { Média (DP) }\end{array}$} & \multicolumn{2}{|c|}{ Indicador de criticidade (IC) } & \multirow{2}{*}{ Classificação } \\
\hline & & & & Média (DP) & Mediana & \\
\hline S01 & $3,04(0,72)$ & $3,23(0,55)$ & $2,00(0,72)$ & $18,64(6,71)$ & 18,00 & Muito crítica \\
\hline S02 & $2,38(0,55)$ & $2,34(0,59)$ & $2,64(0,57)$ & $14,34(4,76)$ & 12,00 & Moderadamente crítica \\
\hline S03 & $2,26(0,52)$ & $2,06(0,62)$ & $2,72(0,55)$ & $12,43(4,99)$ & 12,00 & Moderadamente crítica \\
\hline S04 & $2,22(0,77)$ & $1,94(0,64)$ & $2,77(0,71)$ & $11,27(5,40)$ & 12,00 & Moderadamente crítica \\
\hline S05 & $3,30(0,49)$ & $3,34(0,52)$ & $1,72(0,55)$ & $18,32(5,56)$ & 18,00 & Muito crítica \\
\hline S06 & $2,28(0,53)$ & $2,43(0,52)$ & $2,67(0,54)$ & $14,39(4,04)$ & 12,00 & Moderadamente crítica \\
\hline S07 & $3,27(0,53)$ & $3,34(0,50)$ & $1,79(0,59)$ & $19,00(6,87)$ & 18,00 & Muito crítica \\
\hline S08 & $2,04(0,54)$ & $2,04(0,56)$ & $3,00(0,56)$ & $12,54(5,57)$ & 12,00 & Moderadamente crítica \\
\hline S09 & $2,56(0,63)$ & $2,41(0,66)$ & $2,45(0,64)$ & $14,71(5,78)$ & 12,00 & Moderadamente crítica \\
\hline S10 & $1,15(0,36)$ & $1,25(0,43)$ & $3,53(0,59)$ & $5,25(3,25)$ & 4,00 & Pouco crítica \\
\hline S11 & $1,12(0,38)$ & $1,18(0,45)$ & $3,73(0,51)$ & $5,10(3,62)$ & 4,00 & Pouco crítica \\
\hline $\mathrm{S} 12$ & $1,09(0,41)$ & $1,19(0,48)$ & $3,69(0,56)$ & $4,92(4,03)$ & 4,00 & Pouco crítica \\
\hline $\mathrm{S} 13$ & $1,49(0,58)$ & $1,51(0,58)$ & $3,39(0,61)$ & $8,11(5,41)$ & 4,00 & Pouco crítica \\
\hline S14 & $1,45(0,57)$ & $1,51(0,59)$ & $3,42(0,62)$ & $7,90(5,15)$ & 4,00 & Pouco crítica \\
\hline S15 & $1,61(0,71)$ & $1,64(0,59)$ & $3,24(0,71)$ & $8,76(5,94)$ & 8,00 & Moderadamente crítica \\
\hline S16 & $2,14(0,94)$ & $2,20(0,91)$ & $2,78(0,87)$ & $12,17(6,57)$ & 12,00 & Moderadamente crítica \\
\hline S17 & $1,93(0,76)$ & $2,07(0,77)$ & $2,88(0,76)$ & $11,19(5,47)$ & 12,00 & Moderadamente crítica \\
\hline S18 & $2,96(0,67)$ & $3,15(0,65)$ & $1,98(0,67)$ & $17,60(6,13)$ & 18,00 & Muito crítica \\
\hline S19 & $1,03(0,17)$ & $1,11(0,36)$ & $3,84(0,50)$ & $4,48(2,21)$ & 4,00 & Pouco crítica \\
\hline
\end{tabular}

as da probabilidade de não se comportar habilidosamente oscilaram entre 2,45 e 3,00 .

As situações categorizadas consideradas como muito críticas correspondem a um menor número de casos do inventário $(21,05 \%)$, mas caracterizam-se como aquelas que demandam uma atuação mais precisa. As situações do inventário, cujo o IC foi mais elevado, foram: (S01) quando o aluno se recusa a participar de alguma atividade proposta na aula, eu o incentivo a realizar a tarefa; (S05) quando o aluno desobedece uma regra combinada, eu aplico as consequências previstas; (S07) quando o aluno se distrai da atividade proposta, eu o ajudo a concentrar-se nela; (S18) quando o aluno fica ansioso ao apresentar um trabalho para a turma, eu o oriento a se acalmar. Identificamos que as médias representaram situações mais frequentes e mais desconfortáveis, embora mais prováveis de se agir habilidosamente. Assim, as médias da frequência variaram entre 2,96 e 3,30; já as médias do fator desconforto oscilaram entre 3,15 e 3,34, enquanto as médias da probabilidade de não se comportar habilidosamente ficaram entre 1,72 e 2,00.

\section{DISCUSSÃO}

As situações menos críticas se formaram a partir de baixos níveis de frequência e desconforto. Contudo, possivelmente por serem situações mais raras, os professores não demonstraram uma predisposição a lidar bem com elas em níveis emocionais reguláveis. Portanto, mesmo gerando menor desconforto, como são situações menos frequentes, os professores não estão preparados para ter uma reação habilidosa, o que sinaliza para a importância desse tipo de situação, mesmo sendo considerado pouco crítico, não ser desconsiderado como temática em THS para educadores. Tais treinamentos têm surtido resultados positivos no manejo de situações difíceis no ambiente acadêmico (Lima et al., 2019; Wagner et al., 2019).
Assim, a situação de o aluno ficar tocando em sua genitália $(\mathrm{S} 19 ; \mathrm{IC}=4,48)$ foi considerada a menos crítica dessa categoria, apesar de ter sido a situação que teve a maior média quanto à probabilidade de o professor não agir habilidosamente $(\mathrm{S} 19 ; \mathrm{P}=3,84)$. Apesar de as pesquisas sobre sexualidade e contexto escolar mostrarem que manifestações de sexualidade nesse ambiente costumam ser reprovadas (Zuin, 2008) e que a temática ainda permanece como um tabu (Cedaro et al., 2012; Muniz, 2012), esta situação foi apontada como muito pouco crítica, exatamente por ter baixa ocorrência.

Além disso, o desconforto baixo por parte dos educadores pode estar associado à compreensão de que apenas na 
adolescência é que a sexualidade, eroticamente falando, é aflorada (Guimarães, 2012), embora já se constate nos alunos do segundo ciclo do Ensino Fundamental um despertar para o início da vida sexual (Aerts et al., 2014). Contudo, mesmo entendendo que a vida sexual se inicia na infância, há uma distinção entre os conceitos sexual e genital, sendo que o segundo ganha mais ênfase a partir da adolescência (Guimarães, 2012). Nesse sentido, o fato de ser uma situação menos frequente é o que mais contribui para que seja percebida como menos crítica. Nos casos de ocorrência dessa situação, uma atuação socialmente competente por parte do docente seria "pedir mudança de comportamento" para indicar que a manipulação genital deve acontecer apenas em ambiente privado e não publicamente.

No outro extremo do grupo das situações menos críticas está a apatia do aluno ( $\mathrm{S} 15-\mathrm{IC}=8,76)$, que foi a de maior criticidade desse grupo. A apatia discente também tem seus determinantes. Outros meios de comunicação como a televisão são tão atrativos que a sala de aula precisa de investimento em recursos para conquistar a atenção do aluno. As HSE devem ser consideradas, sem perder o foco de que os objetivos da escola não são meramente a difusão de informações, mas a construção reflexiva de conhecimentos (Coelho \& Maurício, 2016; Correa \& Matos, 2014). Nesse sentido, é requerido que os educadores demonstrem capacidade de inovar e ser criativo preservando a didática científica e estimulando a curiosidade e o engajamento do aluno. Vale ponderar que Bray e Leonardo (2011) evidenciam que professores têm considerado o aluno como apático por si mesmo. Sob essa perspectiva, os docentes podem entender que a apatia é uma quietude do aluno e, portanto, essa condição não seria algo crítico. Isso pode reduzir o questionamento do que pode estar acontecendo com o estudante, responsabilizando-o por essa atitude ou encontrando causas externas à escola para justificála (Ferreira et al., 2016). Essa é uma percepção nociva por conduzir a uma atitude que negligencia medidas interventivas.

$\mathrm{Na}$ categoria das situações moderadamente críticas, por um lado, a situação menos crítica foi a de recusa do aluno na interação com outros colegas (S17; IC $=11,19)$. Por outro, a situação mais crítica deste grupo foi a de os alunos não expressarem suas dúvidas sobre a matéria $(\mathrm{S} 09$; $\mathrm{IC}=14,71$ ). Sobre a primeira situação, é importante ressaltar que o fato de a criança não querer interagir com os colegas levanta questões familiares, além das escolares. A família tem um papel fundamental em oportunizar o desenvolvimento de habilidades sociais na criança a fim de que ela disponha de um repertório efetivo na socialização secundária que encontrará no ambiente escolar (Dessen \& Polonia, 2007). Cabe ao professor desenvolver a HSE proporcionando a socialização do aluno com os pares ou outros significativos do ambiente (Coelho \& Maurício, 2016). Assim, as HSE também são importantes para orientar os comportamentos sociais que $o$ educando pode emitir na interação com os pares.

Quanto à situação de os alunos não expressarem suas dúvidas sobre a matéria, cabe questionar se não haveria uma atitude autoritária por parte dos professores, uma vez que é sabido que comportamentos autoritários dos docentes inibem a expressão de dúvidas sobre a matéria pelos alunos (Cabral et al., 2004) e uma dúvida ou um erro pode suscitar novas possibilidades de prática escolar (Clareto \& Silva, 2016). Mas não se deve confundir autoritarismo com exercício da autoridade, posto que este último pode contribuir para a aprendizagem discente e a própria formação de indivíduos livres (Correa \& Matos, 2014). Assim, docentes que não têm a HSE de "fazer perguntas de sondagem ou desafio" para avaliarem os alunos em conteúdos pertinentes ao tópico de aula em vigor ou não têm a HSE de "manifestar atenção a relato" do educando, terão dificuldades em proporcionar um ambiente que estimule a expressão de dúvidas discentes. $\mathrm{O}$ aluno se desinteressa em fazer colocações na aula porque pode entender que o professor não se interessa pelo seu aprendizado ou relato. Nesse caso, se os alunos não expressam suas dúvidas e, por conseguinte, não obtêm os resultados de aprendizagem de conteúdos formais/ científicos, a própria eficácia da escola pode ser questionada.

Segundo a avaliação dos professores participantes, as situações mais difíceis de serem administradas com alunos em sala de aula envolvem casos corriqueiros como a desatenção para as atividades, a recusa em realizar as tarefas, a ansiedade em falar publicamente e a desobediência de regras combinadas. A análise dos resultados dos indicadores críticos mostra, portanto, que a frequência foi o principal componente que conduziu a avaliação de criticidade das situações pesquisadas. As ocorrências que são raras, mesmo sendo percebidas como desconfortáveis, são menos críticas porque exigem um esforço resolutivo esporádico. Em contrapartida, as situações desconfortáveis e repetidas mobilizam continuamente a energia do professor para administrá-las habilidosamente, potenciando o estresse profissional.

Assim, considerando o agrupamento das situações mais críticas, temos que o fato de o aluno ficar ansioso em apresentação pública foi a situação de menor criticidade ( $\mathrm{S} 18 ; \mathrm{IC}=17,60)$, enquanto a de distração da atividade foi a mais crítica de todas as situações $(\mathrm{S} 07$; IC $=19,00)$. No que diz respeito a esta última, é preciso considerar que a desatenção se caracteriza como um elemento que compromete o rendimento da aula. Pesquisas têm relacionado o baixo desempenho escolar com o Transtorno do Déficit de Atenção com Hiperatividade - TDAH (Cunha et al., 2013; Pastura et al.2005; Reis \& Camargo, 2008).

O manejo da atenção é importante para o indivíduo organizar a sua conduta por meio da seleção consciente dos múltiplos estímulos ambientais, proporcionando uma atenção focal a estímulos específicos (Capovilla $\&$ Dias, 2008). Nesse sentido, o aluno desatento fica comprometido na capacidade de seleção de informações, o que pode dificultar sua aprendizagem. Segundo Tanaka (2008), o psicopedagogo deve favorecer condições para o aluno controlar mais sua atenção, superando problemas 
de aprendizagem. Quanto mais o indivíduo tem controle atencional, mais tem autonomia no aprendizado. Essa análise é relevante porque o aluno pode estar respondendo de forma atenta, durante a aula, a múltiplos estímulos, incluindo os internos como os próprios estados motivacionais, emocionais e de pensamento. Porém, a desatenção pode estar associada a uma "concorrência" de estímulos entre o conteúdo escolar e qualquer outra temática de preferência dos alunos que "prendam a sua atenção", revelando uma dificuldade do ambiente da escola de manter a atenção discente (Silva et al., 2015). Novamente, essa situação exige as HSE que tornam o conteúdo e o ambiente de aprendizagem mais atrativos. Se o aluno não é estimulado em curiosidade ou motivação, provavelmente não conseguirá manter-se atento.

Outra situação difícil em sala de aula é a recusa do aluno em cooperar e participar das atividades propostas pelo professor, o que pode refletir desinteresse ou desmotivação. É preciso refletir até que ponto o próprio docente tem visto a aula como algo maçante e estressante ou um processo de desvendar os fatos da natureza e da vida humana, construindo, nessa última perspectiva, condições pedagógicas para abarcar a curiosidade natural e empolgante de qualquer pessoa em descobrir e "digerir" novos conhecimentos. Santos e Rosso (2012) reconhecem essa questão, ressaltando que diversos elementos pedagógicos - como o despreparo do professor, aulas monótonas e salas lotadas - são deixadas em segundo plano quando se considera que a desmotivação é um fator que tem como único responsável o aluno ou as questões externas à escola.

Ainda sobre essas situações difíceis no ambiente escolar, é preciso ponderar que a ansiedade discente também é um fator compreensível pelo fato de que o aluno é exposto na escola a situações inéditas. O estudante pode sentir ansiedade em virtude de situações de prova, estilo do professor ou exposição pública, por exemplo. A ansiedade discente pode ser desfavorável ao desempenho escolar, uma vez que o organismo está lidando com intensas respostas emocionais internas ao mesmo tempo em que necessita administrar preocupações e decisões de ação (Oliveira \& Sisto, 2002).

Além disso, é preciso considerar que a ansiedade engloba reações emocionais reflexas, ou seja, involuntárias, desencadeadas por um estímulo aversivo condicionado (Coêlho \& Tourinho, 2008). Nesse sentido, o aluno ansioso teme que algo dará errado, não conseguirá o que desejava/esperava ou receberá punições, como humilhação dos colegas. No entanto, apesar de os professores, como expectadores externos, não terem acesso à intensidade e à natureza da ansiedade sentida pelo aluno, em geral avaliam que, nesses casos, há alta probabilidade de realizarem intervenções de regulação emocional que ajudem o aluno. As HSE envolvem expressar compreensão e aceitação do contexto e das condições emocionais que o discente vivencia. Por meio desse monitoramento, o professor tem a oportunidade de se colocar no lugar do aluno, instruindo de forma pertinente ao contexto emocional, assim como incentivando desempenhos futuros baseado nos progressos já conquistados pelo aluno, promovendo a autoconfiança em detrimento da ansiedade de desempenho.

Sobre os limites escolares, é interessante notar que, em geral, as crianças não são desprovidas de um déficit generalizado de seguimento de regras, pois é observável a conformidade instrucional nos jogos e brincadeiras coletivas. As crianças respeitam as regras porque, quando descumprem com o combinado, podem ser punidas ou até excluídas da socialização. Esse é um aspecto relevante porque, se o controle e a comunicação necessários à vida social não forem conduzidos de forma adequada, o indivíduo pode perder a possibilidade de compartilhar o conhecimento acumulado pelo grupo e de absorver a experiência socializada (Correa \& Matos, 2014). Um elemento que contribui para a reflexão acerca de crianças que demonstram dificuldades de seguir regras diz respeito ao comportamento global da criança. Assim, quando um aluno é obediente com um professor, mas comporta-se indisciplinadamente com outro, fica evidenciada que há a capacidade de obedecer a regras, mas a atitude do discente difere de acordo com o docente. Muitos professores, nesses casos, tendem a responsabilizar a família pelo déficit em padrões morais e sociais esperados. Porém, cabe o questionamento se a intervenção docente está acontecendo de forma suficiente e eficaz (Santos \& Rosso, 2012).

Também cabe a dúvida se apenas os docentes do Ensino Fundamental II deveriam ser alvo de desenvolvimento de habilidades sociais, ou se o manejo de situações difíceis no contexto acadêmico nesse nível de ensino também não seria beneficiado por intervenções de THS com os discentes. O estudo realizado por Soares et al. (2019) mostra que, no contexto de situações interpessoais difíceis, há relações entre as habilidades sociais e o coping na adaptação acadêmica. De forma similar, Lima et al. (2019) e Wagner et al. (2019) apontam que o THS para estudantes do Ensino Superior surte efeitos positivos no manejo de situações difíceis. Nesse sentido, seria importante verificar se tais benefícios também seriam obtidos com a realização de THS com crianças e adolescentes que se encontram no Ensino Fundamental II.

Albuquerque e Paracampo (2010) esclarecem a relação entre o seguimento de regras e a vivência de consequências por elas previstas. Para os autores, as consequências vividas alterariam a probabilidade de a pessoa seguir ou não uma nova regra. Assim, se o comportamento foi reforçado (por exemplo, com aprovação social ou outros ganhos) e/ou livrou o indivíduo de punições (por exemplo, nota baixa, reprovação ou desaprovação social), há uma tendência de que o comportamento volte a ocorrer. Dessa forma, o comportamento de seguimento de regras é instalado pelo agente instrucional na medida em que ele dispõe as consequências pelo seguimento ou não, diferencialmente. $\mathrm{O}$ aluno, por sua vez, responde ao que se provou mais forte nas suas experiências: as consequências apontadas pela autoridade ou a permissividade ao deixar o aluno fazer o que deseja (Albuquerque \& Paracampo, 2010). 
Várias são as HSE que estabelecem limites e disciplina e que o professor pode explorar nas diferentes situações. Em contraste, o estabelecimento de uma consequência punitiva recorrente pode trazer efeitos indesejáveis. Nesse sentido, o docente que utiliza uma atitude frequentemente punitiva na tentativa de controlar o comportamento dos alunos pode gerar contracontrole discente. Os efeitos do controle aversivo sobre os alunos podem levar ao desconforto/ ansiedade, associação evitativa da figura do professor, inibição interacional e estratégias de "contra-ataque" e revide (Martins et al., 2013).

Enfim, a pesquisa permite concluir que as quatro situações mais críticas refletem fatores recorrentes e estão direta e intimamente ligadas ao processo escolar de ensinoaprendizagem. Afinal, o professor precisa combinar regras e orientar a disciplina dos alunos que, por sua vez, necessitam estar motivados a se engajar nas atividades de forma atenta e com níveis emocionais gerenciáveis. O estudo evidencia, portanto, prioridades na preparação do professor para o exercício de sua profissão, apontando as situações mais críticas em termos de demanda de HSE. A definição de tais situações baseou-se em uma avaliação dos professores que combinava aquelas que eram mais recorrentes no cotidiano da sala de aula, mais desconfortáveis e com menor probabilidade de os docentes agirem com a correta HSE.

Do ponto de vista acadêmico, o desenvolvimento o indicador de criticidade pode ser útil para outras pesquisas voltadas ao ambiente escolar ou mesmo para investigações de habilidades sociais em outros contextos, caracterizandose como uma nova possibilidade para os pesquisadores da área. Do ponto de vista da contribuição para os profissionais que atuam na área, a identificação dessas situações e o apontamento de seu grau de criticidade pode ser útil para que haja um reconhecimento dos docentes relativamente às situações mais complexas. $\mathrm{O}$ reconhecimento de tais situações e a preparação para administrá-las pode levar a uma redução da ansiedade profissional, com reflexos positivos para a saúde e o bem-estar dos professores. Nesse sentido, o presente estudo contribui para o planejamento da formação docente voltada às situações interpessoais difíceis com os alunos. A argumentação construída vai além da identificação das situações mais críticas, refletindo também sobre as consequências negativas emocionais para o professor e 2a aprendizagem do aluno. Dessa forma, esperamos que este estudo contribua para cultivar o pensamento reflexivo sobre as interações sociais no ambiente educacional, com especial atenção à relação professor-aluno no contexto da sala de aula, o que pode gerar mudanças positivas no pensar e agir pedagógico. Se os professores forem preparados para lidar eficazmente com as situações mais críticas (seja pela recorrência, pelo desconforto gerado ou pela dificuldade de manejo), os efeitos negativos mais intensos da relação interpessoal professor-aluno ocorrerão em níveis mais brandos. Como decorrência, poderíamos esperar relações sociais mais habilidosas no espaço escolar e um ambiente mais propício à aprendizagem.

Entre as limitações do estudo, estão o tamanho e a concentração geográfica (estado do Rio de Janeiro) e de gênero (mulheres) da amostra. Sobre a última, cabe a ressalva de que as mulheres predominam como docentes no segundo ciclo do Ensino Fundamental, sendo que a pesquisa reproduz, portanto, uma desigualdade de distribuição de homens e mulheres que reflete a própria profissão. De qualquer forma, seria importante que estudos futuros ampliassem a abrangência e a representatividade da amostra. Uma amostra mais ampla e diversificada permitiria, inclusive, comparações entre grupos da população de docentes. Outra limitação do estudo, ainda nessa linha das características do público pesquisado, refere-se ao recorte para o segundo ciclo do Ensino Fundamental. É possível que pesquisas realizadas em outras etapas da Educação Básica apontem para diferentes situações críticas relativas às relações interpessoais em sala de aula. Por fim, temos a convicção de que as HSE fornecem uma sistematização de estratégias para lidar e resolver efetivamente conflitos em situações educativas, evitando danos aos envolvidos. Os indicadores de criticidade elaborados podem, portanto, servir ao fomento de novos estudos que associem as HSE às situações difíceis de sala de aula, contribuindo para a melhoria da relação professor-aluno.

\section{REFERÊNCIAS}

Aerts, D. R. G. C., Ottoni, G. T. C. S., Alves, G. G., Palazzo, L. S., \& Santos, A. M. P. V. (2014). Fatores Associados ao Início da Vida Sexual Ativa de Escolares em uma Cidade do Sul do Brasil. Aletheia, 45, 87-100. https://doi.org/10.29327/226091

Albuquerque, L. C., \& Paracampo, C. C. P. (2010). Análise do Controle por Regras. Psicologia USP, 21(2), 253-273. https:// doi.org/10.1590/S0103-65642010000200004.

Alencar, E. M. L. S., \& Fleith, D. S. (2008). Barreiras à Promoção da Criatividade no Ensino Fundamental. Psicologia: Teoria e Pesquisa, 24(1), 59-65. https://doi.org/10.1590/S010237722008000100007

Bray, C. T., \& Leonardo, N. S. T. (2011). As Queixas Escolares na Compreensão de Educadoras de Escolas Públicas e Privadas.
Psicologia Escolar e Educacional, 15(2), 251-261. https://doi. org/10.1590/S1413-85572011000200007

Caballo, V. E. (1996). O Treinamento em Habilidades Sociais. Em V. E. Caballo (Org.). Manual de Técnicas de Terapia e Modificação do Comportamento. (pp. 3-42). Santos Livraria Editora.

Cabral, F. M. S., Carvalho, M. A. V., \& Ramos, R. M. (2004). Dificuldades no Relacionamento Professor/Aluno: Um Desafio a Superar. Paidéia (Ribeirão Preto), 14(29), 327-335. https:// doi.org/10.1590/S0103-863X2004000300008

Camargo, S. P. H., \& Bosa, C. A. (2009). Competência Social, Inclusão Escolar e Autismo: Revisão Crítica da Literatura. Psicologia \& Sociedade, 21(1), 65-74. https://doi.org/10.1590/ S0102-71822009000100008 
Capovilla, A. G. S., \& Dias, N. M. (2008). Desenvolvimento de Habilidades Atencionais em Estudantes da $1^{\mathrm{a}}$ à $4^{\mathrm{a}}$ Sério do Ensino Fundamental e Relação com Rendimento Escolar. Revista Psicopedagogia, 25(78), 198-211.

Carlotto, M. S. (2011). Síndrome de Burnout em Professores: Prevalência e Fatores Associados. Psicologia: Teoria e Pesquisa, 27(4), 403-410. https://doi.org/10.1590/S010237722011000400003

Cedaro, J. J., Vilas Boas, L. M. S., \& Martins, R. M. (2012). Adolescência e Sexualidade: Um Estudo Exploratório em uma Escola de Porto Velho - RO. Psicologia: Ciência e Profissão, 32(2), 320-339. https://doi.org/10.1590/S141498932012000200005

Clareto, S. M., \& Silva, A. A. (2016). Quanto de Inusitado Guarda uma Sala de Aula de Matemática? Aprendizagens e Erro. Bolema: Boletim de Educação Matemática, 30(56), 926-938. https://doi.org/10.1590/1980-4415v30n56a04

Coelho, L. M. C. C., \& Maurício, L. V. (2016). Sobre Tempo e Conhecimentos Praticados na Escola de Tempo Integral. Educação \& Realidade, 41(4), 1095-1112. https://doi. org/10.1590/2175-623660673

Coêlho, N. L., \& Tourinho, E. Z. (2008). O conceito de Ansiedade na Análise do Comportamento. Psicologia: Reflexão e Critica, 21(2), 171-178. https://doi.org/10.1590/S010279722008000200002

Corrêa, C. I. M. (2008). Habilidades Sociais e Educação: Programa de Intervenção para Professores de uma Escola Pública [Tese de Doutorado, Universidade Estadual Paulista]. Repositório Institucional UNESP. https://repositorio.unesp.br/ handle/11449/102264

Correa, R. F., \& Matos, J. C. (2014). O Crescimento da Liberdade como Fim Educacional: A Relação entre o Pensamento Reflexivo e a Liberdade na Obra de John Dewey. Revista Brasileira de Estudos Pedagógicos, 95(239), 11-30. https:// doi.org/10.1590/S2176-66812014000100002

Cury, D. G., Souza, A. A., Silva, S. M. C., \& Castro, L. O. (2012). A Indisciplina na Visão de Professores de uma Escola Pública de Minas Gerais. Perspectivas em Psicologia, 16(2), 72-94.

Cunha, V. L. O., Silva, C., Lourencetti, M. D., Padula, N. A. M. R., \& Capellini, S. A. (2013). Desempenho de Escolares com Transtorno de Déficit de Atenção e Hiperatividade em Tarefas Metalinguisticas e de Leitura. Revista CEFAC, 15(1), 40-50. https://doi.org/10.1590/S1516-18462012005000003

Del Prette, Z. A. P., \& Del Prette, A. (2001). Psicologia das Relações Interpessoais: Vivencias para o trabalho em grupo. Vozes.

Del Prette, A., \& Del Prette, Z. A. P. (2003). No Contexto da Travessia para o Ambiente de Trabalho: Treinamento de Habilidades Sociais com Universitários. Estudos de Psicologia (Natal), 8(3), 413-420. https://doi.org/10.1590/S1413294X2003000300008

Del Prette, Z. A. P., \& Del Prette, A. (2008). Um Sistema de Categorias de Habilidades Sociais Educativas. Paidéia (Ribeirão Preto), 18(41), 517-530. https://doi.org/10.1590/ S0103-863X2008000300008

Dessen, M. A., \& Polonia, A. C. (2007). A Família e a Escola como Contextos de Desenvolvimento Humano. Paidéia (Ribeirão Preto), 17(36), 21-32. https://doi.org/10.1590/ S0103-863X2007000100003

Ferreira, A. C., Santos, E., Ramalho, \& Rosso, A. J. (2016). Representação Social da Indisciplina Escolar. Psicologia: Teoria e Pesquisa, 32(1), 199-208. https://dx.doi.org/10.1590/010237722016012074199208

Garcia, P. S., Fazio, X., \& Panizzon, D. (2011). Formação Inicial de Professores de Ciências na Austrália, Brasil e Canadá: Uma Análise Exploratória. Ciência \& Educação (Bauru), 17(1), 1-19. https://doi.org/10.1590/S1516-73132011000100001.

Gomes, A. S., Pereira, J. W. S., Viveiros, J. O, Mendes, J., Gabriel, M. A. O., Assis, M. R., Carneiro, R. S., Reis, T. P., \&
Nascimento, V. L. P. (2013). Habilidades Sociais e Estresse: Um Estudo com Professores do Ensino Fundamental de Escolas Públicas. Polêm!ca, 12(4), 719-731. https://doi.org/10.12957/ polemica.2013.8640

Gonçalves, M. A. S., Piovesan, O. L., Link, A., Prestes, L. F., \& Lisboa, J. G. (2005). Violência na Escola, Práticas Educativas e Formação do Professor. Cadernos de Pesquisa, 35(126), 635-658. https://doi.org/10.1590/S010015742005000300006

Gondim, S. M. G., Magalhães, M., \& Brantes, C. A. A. (2016). Competências Profissionais: Apresentando um Modelo de Desenvolvimento para Universitários. Em A. B. Soares, L. Mourão, \& M. M. P. E. Mota (Eds.), O Estudante Universitário Brasileiro: Características Cognitivas, Habilidades Relacionais e Transição para o Mercado de Trabalho (pp. 279-298). Appris.

Guilhardi, H. J. (2002). Auto-Estima, Autoconfiança e Responsabilidade. Em M. Z. Brandão, F. C. S. Conte, \& S. M. B. Mezzaroba (Orgs.). Comportamento Humano: Tudo (ou Quase Tudo) que Você Gostaria de Saber para Viver Melhor (pp. 63-98). ESETec.

Guimarães, V. C. (2012). A Concepção Freudiana da Sexualidade Infantil e as Implicações da Cultura e Educação. Revista Educativa, 15(1), 53-66. http://dx.doi.org/10.18224/educ. v15i1.2441

Jacomini, M. A. (2009). Educar sem reprovar: desafio de uma escola para todos. Educação e Pesquisa, 35(3), 557-572. https://doi. org/10.1590/S1517-97022009000300010

Lei $\mathrm{N}^{\mathrm{o}} 12.796$, de 4 de abril de 2013. Altera a Lei $\mathrm{N}^{\circ} 9.394$, de 20 de dezembro de 1996, que estabelece as diretrizes e bases da educação nacional, para dispor sobre a formação dos profissionais da educação e dar outras providências. Recuperado de http://www.planalto.gov.br/ccivil_03/Ato2011-2014/2013/ Lei/L12796.htm, em 08 de fevereiro, 2017.

Lima, C. A., Soares, A. B., \& Souza, M. S. (2019). Treinamento de Habilidades Sociais para Universitários em Situações Consideradas Difíceis no Contexto Acadêmico. Psicologia Clínica, 31(1), 95-121. https://dx.doi.org/10.33208/PC1980$5438 \mathrm{v} 003 \ln 01 \mathrm{~A} 05$

Magalhães, C. A. O. Jr., \& Oliveira, M. P. P. (2005) Formação de professores de ciências para o ensino fundamental. Simpósio Nacional de Ensino de Física, 16. SBF.

Marola, C. A. G., Sanches, C. S. M., \& Cardoso, L. M. (2011). Formação de conceitos em sexualidade na adolescência e suas influências. Psicologia da Educação, (33), 95-118.

Martins, T. E. M., Carvalho Neto, M. B., \& Mayer, P. C. M. (2013). B. F. Skinner e o Uso do Controle Aversivo: Um Estudo Conceitual. Revista Brasileira de Terapia Comportamental e Cognitiva, 15(2), 5-17.

McFall, R. M. (1982). A Review and Reformulation of the Concept of Social Skills. Behavioral Assessment, 4, 1-33. https://doi. org/10.1007/BF01321377

Mourão, L., \& Esteves, V. V. (2013). Ensino Fundamental: Das Competências para Ensinar às Competências para Aprender. Ensaio: Avaliação e Políticas Públicas em Educação, 21(80), 497-512.

Muniz, F. (2012). Sexualidade e Desenvolvimento Humano. UCAM

Oliveira, S. M. S. S., \& Sisto, F. F. (2002). Estudo para uma Escala de Ansiedade Escolar para Crianças. Psicologia Escolar e Educacional, 6(1), 57-66. https://doi.org/10.1590/S141385572002000100007

Osti, A., \& Brenelli, R. P. (2013). Sentimentos de Quem Fracassa na Escola: Análise das Representações de Alunos com Dificuldades de Aprendizagem. Psico-USF, 18(3), 417-426. https://doi.org/10.1590/S1413-82712013000300008

Pastura, G. M. C., Mattos, P., \& Araújo, A. P. Q. Campos, A. (2005). Desempenho Escolar e Transtorno do Déficit de Atenção e Hiperatividade. Archives of Clinical Psychiatry 
(São Paulo), 32(6), 324-329. https://doi.org/10.1590/S010160832005000600003

Perrenoud, P. (1999). Construir as Competências desde a Escola. Artmed Editora.

Perrenoud, P. (2000). Dez Novas Competências para Ensinar. Artmed Editora.

Perrenoud, P., Thurler, M. G., Macedo, L., Machado, N. J., \& Allessandrini, C. D. (2002). As Competências para Ensinar no Século XXI. A Formação dos Professores e o Desafio da Avaliação. Artmed Editora.

Reis, M. G. F, \& Camargo, D. M. P. (2008). Práticas Escolares e Desempenho Acadêmico de Alunos com TDAH. Psicologia Escolar e Educacional, 12(1), 89-100. https://doi.org/10.1590/ S1413-85572008000100007

Rosso, A. J., \& Camargo, B. V. (2013). As Representações Sociais do Desgaste no Trabalho a Partir dos Simbolismos Associados à Docência. ETD - Educação Temática Digital, 15(1), 179-200. https://doi.org/10.20396/etd.v15i1.1301

Santos, E. R., \& Rosso, A. J. (2012). A Indisciplina Escolar nas Representações Sociais de Professores Paranaenses. Psicologia da Educação, (34), 127-157.

Silva, S. P., Santos, C. P., \& Oliveira Filho, P. (2015). Os Significados do TDAH em Discursos de Docentes dos Anos Iniciais. Pro-Posições, 26(2), 205-221. https://doi.org/10.1590/01037307201507708
Skinner, B. F. (1998). Ciência e Comportamento Humano. Martins Fontes.

Soares, A. B., \& Mello, T. V. S. (2009). Habilidades Sociais entre Professores e Não Professores. Revista Brasileira de Terapias Cognitivas, 5(2), 15-27. Disponível por https://doi. org/10.5935/1808-5687.20090012

Soares, A. B., Monteiro, M. C., Souza, M. S. de, Maia, F. A., Medeiros, H. C. P., \& Barros, R. de S. N. (2019). Situações Interpessoais Difíceis: Relações entre Habilidades Sociais e Coping na Adaptação Acadêmica. Psicologia: Ciência e Profissão, 39, e183912. https://doi.org/10.1590/19823703003183912

Tabachnick, B. G., \& Fidell, L. S. (2012). Using Multivariate Statistics. Pearson Education Inc.

Tanaka, P. J. (2008). Atenção: Reflexão sobre Tipologias, Desenvolvimento e Seus Estados Patológicos sob o Olhar Psicopedagógico. Construção psicopedagógica, 16(13), 62-76.

Wagner, M. F., Dalbosco, S. N. P., Wahl, S. D. Z., \& Cecconello, W. W. (2019). Treinamento em Habilidades Sociais: Resultados de uma Intervenção Grupal no Ensino Superior. Aletheia, 52(2), 215-225. https://doi.org/10.29327/226091

Zuin, A. A. S. (2003). Sobre a Atualidade dos Tabus com Relação aos Professores. Educação \& Sociedade, 24(83), 417-427. https://doi.org/10.1590/S0101-73302003000200005 